\title{
ELEMENTOS PARA UMA CRÍTICA DA CULTURA PÓS-MODERNA
}

\author{
João Emanuel Evangelista*
}

Resumo: O artigo tem como propósito realizar uma crítica teórica da“"cultura pós-moderna" e da emergência da "pós-modernidade" nas sociedades"contemporâneas. Para tanto, adota as noções do fetichismo da mercadoria e da"reificação como elementos fundamentais para a realização desta crítica, “desvendando os processos constitutivos do ser social capitalista, nucleados"pela universalização da forma mercadoria para todas as esferas da"organização social. Pretende, ainda, analisar alguns dos mecanismos"socioculturais que operam na modelagem da subjetividade humana e na"reprodução ampliada da sociedade capitalista contemporânea.

Palavras-chave: cultura pós-moderna; acumulação de capital; fetichismo; reificação.“ 


\section{Introdução}

Neste final de século, a vida societária tem sido abalada por uma complexa combinação de crises e transformações sociais profundas, desencadeando processos sociais originais que têm desafiado a sua explicação pelas ciências sociais. Diante das enormes dificuldades teóricas postas pela contemporaneidade, há uma forte tendência a um questionamento rigoroso e, na maioria das vezes, "impiedoso" da tradição teórica constituída em torno dos grandes modelos explicativos "clássicos", até bem pouco vigentes nas ciências sociais, derivados das formulações de Marx, Durkheim e Weber. Chega-se, inclusive, em diagnóstico peremptório, a lhes imputar a existência de uma "crise de paradigmas", na qual sua capacidade elucidativa estaria irremediavelmente comprometida por assentarem suas premissas em categorias mentais típicas do século XIX, que exigiria uma modalidade radicalmente nova de teorização social.

É inegável que são muitos os enigmas que emanaram do desenvolvimento histórico da sociabilidade humana contemporânea e que é igualmente premente a sua decifração intelectual. Dentre as múltiplas problemáticas, destaca-se a questão da constituição da individualidade, num processo de entrecruzamento relacional das dimensões sociais e psíquicas, dos condicionantes objetivos e subjetivos que estão presentes na formação histórica do indivíduo e sua passagem à condição de sujeito na sociedade capitalista. Para essa análise, a esfera da cultura apresenta a maior relevância e possui uma importância decisiva no seu deslindamento.

Aqui, pretendemos tematizar parcialmente esse fenômeno, procurando restabelecer teoricamente algumas das conexões existentes entre a atual "cultura pós-moderna", que se firma cada vez mais como elemento central em nossa dinâmica cultural; e os dilemas vividos pelos indivíduos nos seus esforços para se afirmarem como sujeitos no âmbito de suas relações sociais. Para tanto, as noções de alienação, fetichismo e reificação são fundamentais, pois nos permitem, consecutivamente, desvendar os processos constitutivos do ser social capitalista, nucleados pela universalização da forma mercadoria por todas as esferas da organização social; e esclarecer alguns dos mecanismos socioculturais que operam na modelagem da subjetividade humana numa sociedade burguesa. 


\section{Cultura Pós-Moderna}

Nas últimas décadas tem havido um enorme e diversificado esforço intelectual de reflexão sobre a natureza, as características e as implicações dos fenômenos e das transformações que se processam no âmbito das sociedades humanas. Nessa discussão, a noção de que essas mudanças e os novos problemas vividos pela humanidade significam ou indicam uma situação histórica sem precedentes, configurando a própria "crise da modernidade", tornou-se praticamente um lugar-comum. Houve um "envelhecimento" da era moderna e a "crise da modernidade" é uma constatação consensual e ponto de partida para análises com diagnósticos extremamente diferenciados, feitas a partir de perspectivas teóricas e ideológicas muito heterogêneas.

A chamada "crise da modernidade" tem sido objeto de ampla discussão que está documentada em extensa bibliografia publicada de uns anos para cá. Na maioria das vezes, a modernidade é entendida como um fenômeno abrangente de natureza cultural que tem caracterizado o conjunto da vida intelectual a partir do final do século XVIII e continua, de alguma forma, a vigorar até nossos dias. Numa operação simultânea, a modernidade aparece desvinculada da emergência e afirmação do sistema capitalista e, logo, as mazelas do capitalismo são obliteradas e suas manifestações ideológico-culturais são atribuídas vagamente à modernidade. Os problemas e as contradições da moderna sociedade burguesa são atribuídos à modernidade e tratados como se não tivessem nenhuma relação com a lógica capitalista. Assim, pode-se perfeitamente propor a "superação" da modernidade sem quaisquer rupturas com a ordem social burguesa, e abre-se o caminho para a veiculação de um pensamento "transgressor" que não questiona seriamente a vigência globalizada da lógica do capital, mas, ao contrário, parece-lhe altamente funcional.

Entre essas perspectivas destaca-se o pensamento pós-moderno, que surgiu na década de 70 nos países capitalistas industrializados, inicialmente dirigido à tematização das questões estéticas e arquitetônicas, tendo, desde então, uma crescente difusão e repercussão no mundo da cultura, incidindo amplamente na elaboração da teoria social e na reflexão filosófica. Como o próprio termo sugere, o 
pensamento pós-moderno se afirma como expressão intelectual de uma suposta nova ordem societária que se estaria formando em contraposição à modernidade em crise.

O pensamento pós-moderno é a expressão teórica e cultural de uma nova situação sócio-histórica: a condição pós-moderna. O pensamento pós-moderno instauraria uma nova modalidade de "racionalidade" e de cultura, que é a expressão de um conjunto de transformações econômicas, sociais e políticas, produzindo uma mudança qualitativa nas instituições da sociedade moderna. Assim, o pensamento pós-moderno significaria, simultaneamente, uma crítica e uma ruptura com a modernidade, com implicações que atingem desde a vida cotidiana até a produção do conhecimento social.

As mudanças experimentadas pelas sociedades contemporâneas, nos últimos tempos, alteraram as formas como os homens sentem e representam para si mesmos o mundo onde vivem. Há uma enorme dificuldade de sentir e representar o mundo contemporâneo, pois a sensação vigente é de irrealidade, de vazio e de confusão. A capacidade de representação da razão humana estaria se esvaziando progressivamente. Estaríamos diante do predomínio de um princípio esvaziador que atuaria em todas as esferas do mundo e da sociedade moderna, envolvendo suas instituições e suas formas simbólicas e imaginárias. Assim, por exemplo, estariam se processando a desreferencialização do real, a desmaterialização da economia, a desestetização da arte, a desconstrução da filosofia, a despolitização da sociedade e a dessubstancialização do sujeito. ${ }^{1} \mathrm{Ou}$ seja, tudo o que existe estaria marcado pela efemeridade, pela fragmentação, pelo descentramento, pela indeterminação, pela descontinuidade, pelo ecletismo das diferenças e pelo caos paradoxal. ${ }^{2}$

O cotidiano constitui o espaço onde se encontram condensados os traços definidores da pós-modernidade. Atualmente, a nossa cotidianidade está atravessada pela individualização, pelo consumismo e pelo predomínio da informação. Através da publicidade, que invadiu todas as brechas da vida do homem - no trabalho, na escola, no lazer, nas ruas, nos transportes ou em casa -, ocorreu a estetização dos objetos de consumo e a erotização e a personalização das mercadorias. As vitrines e o vídeo passaram a ser dimensões indispensáveis para existência de 
todas as coisas do mundo. A realidade social se desmaterializou e passou a ser o domínio do signo, que transformou o cotidiano na vivência imediata de simulacros, instaurando-se a hiper-realidade pela generalização da informação na sociedade informatizada de massas.

Para Lyotard, a sociedade pós-moderna se configura como uma nebulosa de "jogos de linguagem" que tecem os vínculos sociais. Os sujeitos sociais dissolvem-se pela atomização do social em redes flexíveis de jogos de linguagem heteromórficos, que se disseminam e que não podem ser disciplinados por regras gerais. A realização diferenciada e heterogênea de jogos de linguagem cria instituições sociais "em pedaços", de onde emanam regras de enunciação que definem o que pode ser dito e como pode ser dito. Porém, esses poderes institucionais, dispersos em nuvens de elementos narrativos, não estabelecem limites absolutos, pois essas regras de enunciação são mutáveis e flexíveis. A sociedade, assim, teria se transformado num conjunto descentrado e pluralista de redes de enunciado de diferentes tipos. ${ }^{3}$

Numa perspectiva distinta, mas complementar a essa, Baudrillard afirma que a comunicação de massa, que caracteriza a sociedade contemporânea, ao autonomizar a produção de signos em relação a qualquer referente concreto, transformou a realidade em simulacro: um mundo artificial que substitui o mundo real. Isso ocorre através da produção de signos que tentam ser mais reais do que a própria realidade, gerando-se uma hiper-realidade. As novas tecnologias e processos comunicativos terminam produzindo linguagem e signos que são autoreferentes. Haveria um esvaziamento da realidade material com a emancipação dos signos que produzem uma realidade aparente como puro simulacro. Como exemplo acabado disso, a publicidade atuaria como um jogo sobre si mesma, deixando de existir diálogo entre o emissor e o receptor, que são as massas inertes, fascinadas com o poder da comunicação. Assim, as mercadorias perdem sua materialidade e seu valor de uso e só adquirem sentido através da publicidade, que faz da imagem um simulacro da mercadoria. A comunicação de massa transferiria a vivência no real para a vivência no signo. Portanto, a cultura pós-moderna seria a cultura do simulacro. ${ }^{4}$

Entretanto, para Jameson - em uma instigante abordagem teórica que supera certos limites da análise frankfurtiana da indústria cultural, 
mesmo tendo-a como premissa - o pós-modernismo significa a lógica cultural do capitalismo avançado ou tardio. A produção cultural foi assimilada pela produção de mercadorias em geral, onde a inovação e a experimentação estéticas passaram a ter uma função estrutural essencial diante da necessidade frenética de produzir uma infinidade de novos bens com uma aparência cada vez mais nova. A cultura, mais do que nunca, passou a ser uma esfera central do processo de reprodução social, invadindo e recobrindo todos os espaços da sociabilidade. Com a pós-modernidade, há "a transformação da cultura em economia e da economia em cultura. É uma imensa 'desdiferenciação' [...], na qual as antigas fronteiras entre a produção econômica e a vida cultural estão desaparecendo". ${ }^{5}$

A expansão do capital não somente "atingiu" a dimensão cultural, mas as imagens, as representações e as formas culturais se tornaram uma área de atuação fundamental do mercado capitalista. Os componentes da esfera cultural foram convertidos plenamente em mercadorias. Com a expansão das novas tecnologias informacionais, a produção e a circulação de informação passaram a ser uma das mercadorias mais importantes no capitalismo tardio ou multinacional. Assim, os conflitos e as contradições, antes relacionados principalmente à produção material, espalham-se e invadem também a produção cultural. Tudo isso se faz acompanhar de uma profunda mudança nos hábitos e atitudes de consumo e nas relações intersubjetivas que ocorrem no mundo cotidiano. ${ }^{6}$

É ainda Jameson que nos apresenta a cultura pós-moderna a partir de alguns traços constitutivos que lhes seriam peculiares. ${ }^{7} \mathrm{O}$ pósmodernismo inaugura uma nova superficialidade, onde o mundo objetivo é convertido em um conjunto de textos e simulacros, e as coisas são reduzidas à imagem de suas superfícies externas. Há, também, um enfraquecimento da historicidade, em que o passado é tomado como uma vasta coleção de imagens aleatórias, que são combinadas de múltiplas formas a partir do presente. Essa presentificação do passado e do futuro funda um discurso "esquizofrênico" sobre a história. Assim, não por acaso, no pós-modernismo, as categorias espaciais substituem as categorias temporais, cuja dominância é uma das maiores características do modernismo. Surge, outrossim, uma nova experiência 
do espaço, em que a configuração de um hiperespaço com a constituição de redes mundiais de comunicação, possibilitadas pela descoberta e difusão das novas tecnologias informacionais, transcende a anterior capacidade de localização pelo indivíduo e torna evidentes as dificuldades de representação do real pelas atuais categorias mentais. Isso terá como rebatimento estético o desaparecimento do sujeito como produtor artístico-cultural autêntico e original e o fim da busca por um estilo pessoal. Emerge, enfim, uma nova sensibilidade, marcada pela intensidade emocional, que celebra o advento do pastiche - colagem de estilos passados - como nova solução estética descompromissada com qualquer perspectiva de crítica radical e de transformação da ordem societária.

\section{Alienação, Fetichismo e Reificação}

A alienação é um fenômeno que apresenta múltiplas formas de objetivação no transcurso da história. Possui sua gênese na história, com o surgimento da divisão social do trabalho e da propriedade privada. No entanto, seus efeitos não podem ser reduzidos a essas determinações econômico-sociais. Com o tempo, alienação se autonomiza como fenômeno e suas causalidades desaparecem socialmente, produzindo processos sociais que possuem uma inércia própria e tendem a ficar imunes às diversas transformações sociais. A alienação introduz uma refração fundamental nas relações dos homens entre si e dos homens com a natureza. Sob seus influxos, dá-se uma ruptura essencial no processo de formação dos sujeitos em suas necessárias interações com os objetos que lhes são circundantes. Rompe-se a relação entre sujeito e objeto, que sempre têm uma definição relacional recíproca. Os sujeitos são apartados dos objetos, que se autonomizam diante dos sujeitos, invertendo-se a condição ativa e particular dos elementos desse processo e instaurando-se a subordinação dos sujeitos aos objetos. Os sujeitos, possuidores de capacidade volitiva e atividade criadora, perdem o controle sobre si mesmos e sobre os produtos de sua atividade. Assim, os homens são, literalmente, rebaixados de sua condição de sujeitos à condição de simples objetos. Não mais conseguem perceber e reconhecer as formas sociais, em que estão imersos, como o resultado 
de sua própria vontade e atividade sociais. Os homens passam a ignorar, portanto, o caráter dos vínculos que estabelecem entre si . Isso configura o conjunto da vida social e as relações produtivas que mantêm com a natureza.

O trabalho é a protoforma da práxis que caracteriza o gênero humano. É através do trabalho que o homem se hominiza - torna-se efetivamente homem - e humaniza a natureza, imprimindo-lhe a marca da vontade, das necessidades e dos carecimentos humanos. Ao transformar a natureza, em busca de sua sobrevivência material, o homem dela se distingue e produz, a partir dessa experiência mesma, a sua vida coletiva como sociedade e cultura na história. $\mathrm{O}$ trabalho, pois, representa a mediação necessária na constituição do homem social como sujeito nas suas relações com o objeto - o mundo histórico-natural.

É justamente no trabalho que a alienação encontra a sua forma mais emblemática no mundo moderno. Com a alienação do trabalho, há uma inversão radical na práxis sócio-humana. Se era através do trabalho criador que o homem se punha como sujeito perante os outros homens e a natureza, com o trabalho alienado o homem é degradado à condição de objeto na trama de suas relações sociais. Aqui, a alienação alcança ao mesmo tempo diversas formas, que estão articuladas e se reforçam reciprocamente. $\mathrm{O}$ trabalho alienado implica a alienação do trabalhador em relação ao produto de sua atividade e à sua própria atividade. E, extrapolando a simples dimensão técnico-material na produção, a alienação atinge mais profundamente o gênero humano ao instituir uma relação alienada entre o homem trabalhador e os demais homens, dos homens consigo mesmos e dos homens com a natureza. A alienação do trabalho suprime a condição de sujeito do homem em face dos resultados do seu trabalho e ao seu próprio trabalho, além de inverter o caráter de suas relações sociais com outros homens e com a natureza, no âmbito das formas socioculturais de sua vida societária. ${ }^{8}$

$\mathrm{Na}$ sociedade capitalista, a universalização da produção de mercadorias transforma tudo em mercadoria e, até mesmo, produz homens-mercadorias com o trabalho assalariado. A alienação opera pondo a mercadoria no lugar de elemento fundante de toda sociabilidade, desfazendo os laços e os vestígios sócio-históricos que permitiram o aparecimento do sistema de produção de mercadorias e que garantem 
a sua reprodução social. A mercadoria surge naturalmente como sujeito, transcendendo a história, perante os homens-mercadorias. Todas as relações desses homens entre si e com a natureza sofrem necessariamente a mediação da mercadoria, do dinheiro e do capital. A mercadoria aparece como autônoma e exerce uma determinação unilateral sobre os homens. Desse modo, a coisa (mercadoria) se torna o centro irradiador da sociabilidade e subordina sujeitos e objetos, transformando-os em coisas. As relações intersubjetivas são coisificadas e o homem vê a si mesmo e aos outros como coisas. ${ }^{9}$

A generalização da produção capitalista faz da sociedade burguesa um mundo crivado de manifestações fantasmagóricas, com a reverberação social do fetichismo da mercadoria. O fetichismo é a modalidade histórica e forma concreta da alienação nas condições mercantis.

Com o fetichismo da mercadoria, a alienação se afirma e se desenvolve através da cristalização em coisas. O produto do trabalho humano se aliena do seu produtor e se põe como uma coisa independente dele, dotada de autonomia e vontade próprias. É por isso que, na sociedade capitalista, a reificação ${ }^{10}$ é a forma particular da alienação, onde o fetichismo da mercadoria está disseminado pelo ser social e matriza a própria constituição da subjetividade humana. A alienação adquire um caráter objetual - "coisal" - com a reificação do conjunto das relações sociais, passando a atribuir qualidades humanas a formas exteriores de coisas; e, inversamente, qualidades coisais às formas sócio-humanas. ${ }^{11}$ Como o fetichismo da mercadoria representa a matriz dos processos alienantes e da reificação das relações sociais, é a partir da análise da mercadoria mesma que os "hieróglifos" sociais, em que se transmutou a sociedade burguesa, podem ser devidamente elucidados.

Ao analisar a mercadoria, Marx descobre que o "segredo" contido no fenômeno do fetichismo reside na própria forma da mercadoria. ${ }^{12}$ Já na sua forma simples, pode-se verificar que o valor de uma mercadoria, que corresponde ao tempo socialmente necessário à sua produção, somente se expressa através do processo de troca com outras mercadorias. $\mathrm{O}$ valor de uma mercadoria não se manifesta isoladamente, mas necessariamente por intermédio do "corpo" de outras 
mercadorias. A expressão do valor exige a sociabilidade de outras mercadorias, no processo de circulação, para ganhar visibilidade e materialidade. $\mathrm{O}$ valor de uma mercadoria não pode se exprimir por si mesmo e requer obrigatoriamente uma relação social com outra(s) mercadoria(s), que passa(m) a espelhar o seu valor.

$\mathrm{Na}$ forma simples do valor, num processo fortuito de troca, temos sempre uma equação entre a forma relativa e a forma equivalente do valor de uma mercadoria. Nessa equação, a mercadoria que atua como equivalente possui a função social de certificar o valor e a quantidade de valor contidos na mercadoria que está na posição da forma relativa. A mercadoria equivalente empresta o seu "corpo" material para espelhar o valor de certa mercadoria, que é, assim, equiparada nessa troca.

Com o desenvolvimento do processo de troca, uma determinada mercadoria serviu de expressão do valor de todas as demais mercadorias, facilitando a efetivação e a expansão das relações mercantis, ao operar como equivalente geral na esfera da circulação. É a partir dessa forma desenvolvida do valor que se explica, por sua vez, o surgimento do dinheiro como forma propriamente burguesa do valor. Com o dinheiro assumindo a posição de equivalente geral, criouse uma mercadoria especial que ocupa o centro do processo de troca e, o que é mais importante, da própria sociabilidade, atribuindo valor a todas as outras mercadorias.

Com o dinheiro como forma do valor, ocorre a hipostasia do processo de circulação e o cancelamento dos vestígios materiais e sóciohistóricos da produção do valor das mercadorias. A representação substitui a realidade: o trabalho desaparece socialmente como fonte do valor. Então, o valor das mercadorias parece derivar do dinheiro/ equivalente geral, como se isso fosse sua propriedade natural. O dinheiro surge aos olhos dos homens como o demiurgo da vida social. Toda a sociabilidade passa a ser mediada pelo dinheiro, que dá significação social a todas as mercadorias e à própria atividade dos homensmercadorias. Assim, o dinheiro ocupa a posição de sujeito fundante do conjunto das relações sociais que caracterizam a dinâmica da sociedade capitalista.

Desse modo, Marx elucida que o caráter "sobrenatural" do fetichismo provém da forma mercadoria, que precisa se relacionar 
socialmente com outra(s) mercadoria(s) - "coisa" que mantém relações sociais com "coisa" - para expressar o seu valor. Instaura-se, então, uma lógica societária centrada nas relações sociais entre "coisas", que emana das "coisas" e transcende a vontade humana. O fetichismo adere a todos os produtos do trabalho, quando são produzidos como mercadorias. Há uma transferência para a "coisa" das qualidades, poderes e forças que são acionados pelos homens e são atributos humanos, com a alienação do trabalho do homem e a reificação de suas relações sociais. Na sociedade capitalista, os homens estão irremediavelmente subsumidos à "coisa": à mercadoria, ao dinheiro, ao capital.

O fetichismo da mercadoria e a reificação das relações sociais constituem a forma objetiva do ser social no mundo do capital. Por isso, a sua existência sócio-histórica independe da consciência que os indivíduos possam ter desses fenômenos. A ordem social burguesa possui uma aparência de algo dado desde sempre, de um conjunto inorgânico e justaposto de coisas isoladas e independentes umas das outras e especialmente dos homens, que escapa ao controle de todos e a que o indivíduo deve se adaptar para "viver". As relações sociais são vividas e percebidas como um processo inatingível em seu sentido e em sua dinâmica. O mundo social institucionalizado dirige a existência humana como instância alheia, incógnita e impessoal, numa aparência de inexorabilidade e fatalidade dos processos de produção e reprodução da vida social. ${ }^{13}$

Todavia, os efeitos do fetichismo e da reificação não são apenas "externos". No capitalismo, a própria estruturação psíquica da subjetividade humana está submetida a esses fenômenos. A subjetividade é modelada pela forma mercadoria e o fetichismo está situado no próprio inconsciente do "sujeito". A constituição do sujeito é balizada por uma dialética conflitiva entre a internalização do sujeitamento e o recalque e a repressão da subversão do sujeitamento. $\mathrm{O}$ sujeito se afirma, num conflito entre a coisa e a pessoa, pelas manifestações possíveis das dimensões recalcadas e reprimidas de sua subjetividade. ${ }^{14}$ 


\section{Reificação, Imagem e Sociedade do Espetáculo}

A partir das inovações na base técnica e na organização do trabalho promovidas pelo taylorismo fordismo, a sociedade capitalista tornouse um sistema de produção em massa e de consumo de massa de mercadorias. A criação de um mercado de consumo de massa implicou profundas transformações culturais, pois foi indispensável que as pessoas fossem ressocializadas como consumidoras, pondo-se fim à produção doméstica e estimulando-se crescentemente a dependência ao mercado para a satisfação das necessidades e carecimentos humanos. O lançamento de novas mercadorias requeria que se desestimulassem a iniciativa e autoconfiança dos indivíduos em seus próprios recursos e capacidades. O mundo das mercadorias é, então, apresentado como um mundo sedutor de sonhos e de possibilidades de realização das fantasias dos consumidores. Esse mundo do consumo parece existir apenas para satisfazer os desejos de indivíduos cada vez mais passivos em face das mercadorias e do mercado e dependentes deles. ${ }^{15}$

Nessa sociedade de consumo, os meios de comunicação de massa e a publicidade invadem todo o cotidiano dos indivíduos e atuam "educando" as massas para ter um inesgotável apetite por novos bens e por novas experiências e satisfação pessoais. É necessário convencer as pessoas a consumir a produção em massa de novas mercadorias que chegam incessantemente ao mercado. $O$ consumo ganha o estatuto de atividade privilegiada capaz de suprimir todos os males da vida moderna. A publicidade cria um consumidor que deve estar permanentemente insatisfeito, intranqüilo, ansioso e entediado, para que o consumismo se afirme como verdadeiro modo de vida nas sociedades capitalistas. Configura-se aquilo que Lasch chamou de "cultura do narcisismo".

$\mathrm{Na}$ visão do senso comum, em geral, confunde-se o narcisismo com o hedonismo, o auto-interesse, o egoísmo e a indiferença social. No entanto, o narcisismo, muito mais do que individualismo anti-social, significa uma individualidade plasmada numa cultura em que não mais se distinguem a realidade e o reflexo da realidade, e não mais se consegue diferenciar a fantasia da realidade. Não há distinção entre o 
eu e o mundo dos objetos. As fronteiras entre o indivíduo e o mundo exterior circundante foram apagadas. A personalidade narcisista atravessa uma profunda crise de identidade, pois o eu narcisista não tem segurança dos seus próprios limites. $\mathrm{O}$ narcisismo produz a disposição de ver o mundo como um espelho ou como uma projeção dos próprios medos e desejos do indivíduo. ${ }^{16}$

É assim que surge um conjunto de novos descontentamentos. O consumo de mercadorias promete suplantar o tédio, o cansaço, a futilidade e o vazio, vividos cotidianamente pelas pessoas, jogando sedutoramente com o mal-estar peculiar à vida moderna. $\mathrm{O}$ consumo de mercadorias transforma-se em alternativa ao protesto e à rebelião sociais. Com isso, porém, o consumo cria e exacerba novas formas de infelicidade, com a proliferação de um "clima" geral de insegurança pessoal, de ansiedade por status social e de institucionalização da inveja nas relações sociais. A mercadoria passa a conferir prestígio social a quem a consome, configurando-se uma sociedade dominada fundamentalmente pelas aparências, onde os múltiplos e complexos sentidos do ser humano estão subordinados ao exclusivo sentido do ter. ${ }^{17}$

A sociedade onde vivemos está enredada numa trama cultural marcada por um amálgama de elementos aparentemente díspares, onde o indivíduo cada vez mais sente dificuldades de se firmar em algo que seja minimamente estável e lhe assegure alguma sensação de tranqüilidade e bem-estar íntimos. Estamos imersos num tempo em que os valores dominantes estão polarizados em torno do consumismo, do individualismo, do hedonismo e do esoterismo. Ao mesmo tempo em que tenta e vai conseguindo sobreviver, o homem está envolto por um estado permanente de insatisfação, ansiedade, intranqüilidade, apatia e uma enorme sensação de vazio interior na vivência do seu cotidiano.

O psicanalista Jurandir Freire Costa, ao examinar o problema do narcisismo na cultura contemporânea, diz que a sociedade capitalista respondeu ao mal-estar da Cultura

[...] criando o presente de nossas ilusões. No universo do lucro, o político tornou-se o mercado, o sujeito tornou-se o objeto, e a felicidade, o consumo. É o reino narcísico do objeto como espelho do sujeito [...] Um dos tópicos centrais da fantasia narcísica de 
felicidade é o da realização imediata do desejo. O mercado fabricou a solução imaginária. Fez da felicidade consumo de coisas que, supostamente, podemos ter quando e como quisermos [...] Com dinheiro, poder e sucesso temos tudo o que é preciso.

Para ele, a felicidade do mercado afirma "ame os objetos, eles jamais dizem 'não'! São dóceis e programados para realizar o que julgamos saber sobre a satisfação de nossos desejos". ${ }^{18}$ De forma peremptória, é complementado por Contardo Calligaris, também psicanalista, que fala do universo narcísico como um mundo onde os espelhos somos nós:

Vivemos em um mundo onde talvez a subjetividade só encontre consistência pelas imagens que o repertório midiático nos propõe como amáveis (não tanto por nós, mas pelos outros). A cada esquina nos deparamos com espelhos invertidos que não nos refletem: são imagens pintadas que nos delegam paradoxalmente a tarefa de refleti-las $[\ldots]^{19}$

A sociedade burguesa transformou-se, portanto, numa "sociedade do espetáculo", ${ }^{20}$ onde a reprodução da cultura se faz através da proliferação de imagens de todos os tipos. A produção e o consumo de massa de mercadorias são acompanhados pela difusão sem precedentes da imagem. A vida moderna é tão maciçamente invadida pela imagem, que a própria experiência humana é percebida e vivenciada como um mundo de imagens oscilantes, onde é cada vez mais difícil separar fantasia e realidade.

A cultura de massas parece dissolver o mundo das coisas materiais e o substituir por um mundo vago e fluido de imagens, abalando profundamente o nosso senso de realidade. Assim, a realidade parece coincidir cada vez mais com as imagens que dela se produzem e veiculam. A realidade sofre um processo de "desmaterialização", sendo substituída por imagens e por um mundo especular. Há uma autonomização das imagens em relação aos seus referentes, aparecendo, mais exatamente, como se fossem auto-referentes. Desse modo, a imagem e a produção de imagens ocupam uma posição de centralidade na vida societária e na cultura contemporâneas. 
A análise do fato de a sociedade contemporânea ser crivada e dominada pelas imagens não deve, contudo, ser conduzida em tom de alarme apocalíptico, no qual "órfãos de valores e tradições, idealizaríamos e amaríamos cegamente qualquer imagem que a cultura de massa sugere como modelo possível (CALLIGARIS, 1995)". E "mesmo que o império das imagens seja total, ele não se confunde com o império do mal ou com o triunfo definitivo da alienação. Apesar da mídia comum, nem todas as imagens se valem (CALLIGARIS, 1995)”. Como nos prescreve ainda Calligaris,

[...] não é preciso condenar nossos tempos como época de um obscurantismo caleidoscópico, onde só vale a sedução das imagens e todas as imagens nos seduzem. Seria melhor, ao contrário, abandonar o fácil tom do apocalipse e se perguntar como acontece que, justamente neste mundo de imagens (e não apesar dele), é de fato possível comparar, recusar, escolher. Em breve, agir e pensar. ${ }^{21}$

Aqui, mais uma vez, fica evidente as potencialidades heurísticas da noção de práxis dentro de uma perspectiva radicalmente assentada numa razão crítica.

Jameson adverte, também, para evitar o reducionismo no tratamento da cultura, que, apesar da análise da mercantilização da cultura de massa feita pela Escola de Frankfurt ainda não estar esgotada, nem tudo pode ser visto pela ótica da manipulação. É necessário repensar a oposição entre "alta cultura" e "cultura de massa", através de uma abordagem dialética que supere essa dicotomia, considerando-as fenômenos relacionados e interdependentes na cultura contemporânea. Mais ainda: a "alta cultura" e a "cultura de massa" são formas gêmeas e inseparáveis na produção cultural do capitalismo tardio, que instaura esse duplo padrão cultural como contradição objetiva.

Tanto a "alta cultura" quanto a "cultura de massa" trabalham o imaginário social como seu substrato:

[...] a diferença é que onde o modernismo tende a manusear esse material produzindo estruturas compensatórias de vários tipos, a cultura de massa os recalca por meio da construção narrativa de 
resoluções imaginárias e da projeção de uma ilusão óptica de harmonia social. ${ }^{22}$

É por isso que Jameson chama a atenção para o fato de que os produtos da cultura de massa não podem ser ideológicos sem ser também, direta ou indiretamente, utópicos e transcendentes. A dimensão manipulatória da cultura de massa, para atuar eficazmente, precisa oferecer em contrapartida um mínimo de autenticidade pela satisfação das mais profundas e fundamentais esperanças e fantasias presentes, sob a forma de utopia, no imaginário da sociedade. Exatamente porque as formas culturais consistem em soluções imaginárias para os conflitos e as contradições que perpassam historicamente toda a complexa sociabilidade humana. ${ }^{23}$

\section{Para uma crítica da Cultura Pós-Moderna}

A vida societária foi completamente tomada e saturada por todo tipo de imagens que permeiam o conjunto das relações sociais e são uma mediação necessária da sociabilidade humana no mundo contemporâneo. Ao mesmo tempo, ocorreu um avassalador processo de atomização social do indivíduo, que passou crescentemente à condição de "espectador" nessa sociedade do espetáculo, configurando o fenômeno que alguns denominam cultura do narcisismo, para designar os efeitos simbólicos e imaginários provocados pela produção e consumo massivos de mercadorias nas sociedades capitalistas ou que outros qualificam de pós-modernidade, para designar uma profunda mudança social que indicaria a emergência de uma nova situação histórica.

Os teóricos do pós-moderno trabalham a partir da premissa, nem sempre explicitada, de que teria havido uma ruptura econômica fundamental entre as antigas sociedades industriais e as sociedades contemporâneas, que seriam sociedades pós-industriais. As sociedades industriais se caracterizavam pela produção de bens materiais, com a utilização de energia, através de grandes organizações empresariais hierárquicas e emprego de força de trabalho desqualificada ou semiqualificada. De outro lado, as sociedades pós-industriais seriam 
caracterizadas pela produção de serviços, com a utilização de informação, em pequenas organizações empresariais descentralizadas que empregam profissionais qualificados. Neste último tipo de sociedade, a difusão de novas tecnologias, como a informática, e a automação do processo de trabalho trariam o fim do trabalho operário e do conflito capital/trabalho, aumentando a liberdade e a autonomia do trabalhador superqualificado, que não viveria mais uma situação de exploração e de alienação.

Nessas sociedades pós-industriais, o Estado e as formas políticas teriam também sofrido uma profunda mudança. Com a fragmentação da sociedade e a desmaterialização da produção, desapareceriam as antigas contradições sociais de natureza estrutural e os sujeitos políticos universais, como as classes sociais, que atuavam com o objetivo de conquistar ou de manter o poder político centralizado no Estado moderno. Agora, com a pulverização do poder numa miríade de redes capilares espalhadas pela sociedade civil, os agentes da política seriam sujeitos políticos particulares e transitórios, constituídos por grupos com fins específicos e com demandas próprias, que atuariam em campos setoriais de dominação sob formas singulares de resistência. As lutas políticas atuais deslocaram os interesses universais para dar lugar a particularidades de gênero, étnicas, sexuais, ecológicas, etc. Além disso, as disputas no campo político passaram a ser regidas pela lógica da política do espetáculo para as grandes massas. A busca do convencimento pela argumentação racional e pela apresentação de projetos políticos, característica da política na modernidade, teria dado lugar à sedução das imagens no cenário de massas da política pósmoderna.

$\mathrm{Na}$ esfera estética, foi onde teve início o uso do termo "pósmoderno" para cuidar do movimento de crítica e negação do modernismo que acontecia na arquitetura e na literatura, a partir do final dos anos 50 e início da década de 60 . Num primeiro momento, o pós-moderno se insurgiu contra o "alto modernismo" instituído e oficializado como padrão estético. As novas tecnologias, como a televisão, o vídeo e o computador, eram vistas com grande entusiasmo como novas possibilidades de produção artística. Com o esgotamento do seu impulso iconoclasta, o pós-modernismo entra em uma fase mais 
apática e despolitizada. O pós-modernismo provoca o fim das fronteiras entre a arte popular e de massas e a arte erudita, fazendo desaparecer a figura do artista como sujeito da produção artística e eliminando a ideologia do novo e do vanguardismo modernista. A arte pós-moderna vai usar o passado como matéria-prima para o pastiche de antigas obras, pela superficialidade e pelo recurso ao ecletismo e à colagem de estilos e de linguagens, no seu esforço de estetização do cotidiano. ${ }^{24}$

A análise mais cuidadosa desse conjunto complexo e multifacético de fenômenos que marcam as sociedades contemporâneas não indica propriamente uma ruptura radical com a modernidade e a sua ultrapassagem com a configuração da pós-modernidade como novo momento histórico-social. As mudanças que se processam desde a vida cotidiana, passando pela economia e pela política e culminando na cultura, apontam, simultaneamente, para a generalização e o aprofundamento da lógica social de produção de mercadorias e de acumulação de capital, com a entrada numa nova fase do capitalismo que provoca e requer uma reestruturação profunda da cotidianidade e da cultura, com evidentes repercussões em todo o processo social. $\mathrm{O}$ que há, portanto, é uma ruptura centrada na esfera abrangente da cultura, tendo o pós-modernismo e o pensamento pós-moderno como a sua expressão mais adequada. Nessa fase contemporânea do capitalismo, a cultura é submetida plenamente ao movimento de produção e reprodução do capital, constituindo-se em espaço de expansão da produção de mercadorias e de acumulação capitalista, intensificando exponencialmente o fenômeno da reificação que também ocupa a esfera da cultura e generaliza os seus efeitos sobre os signos e as imagens que se objetivam na nossa vida cotidiana. Ademais, muitas das características apresentadas como demonstração da instauração da "pós-modernidade" são, na verdade, traços constitutivos da própria modernidade. Desde Baudelaire, o primeiro a refletir sobre as suas implicações estéticas, que a vida moderna é pensada como realidade dominada pelo transitório, pelo fugidio e pela contingência, de onde cabia ao artista captar-lhe o que havia de imutável e de eterno. É nesse sentido que Berman descreve a vida moderna como um redemoinho permanente a desintegrar tudo o que encontra à sua frente: 
Existe um tipo de experiência vital - experiência de tempo e espaço, de si mesmo e dos outros, das possibilidades e perigos da vida que é compartilhada por homens e mulheres em todo o mundo, hoje. Designarei esse conjunto de experiências como "modernidade". Ser moderno é encontrar-se em um ambiente que promete aventura, poder, alegria, crescimento, autotransformação e transformação das coisas em redor - mas ao mesmo tempo ameaça destruir tudo o que temos, tudo o que sabemos, tudo o que somos. A experiência ambiental da modernidade anula todas as fronteiras geográficas e raciais, de classe e nacionalidade, de religião e ideologia: nesse sentido, pode-se dizer que a modernidade une a espécie humana. Porém, é uma unidade paradoxal, uma unidade de desunidade: ela nos despeja a todos num turbilhão de permanente desintegração e mudança, de luta e contradição, de ambigüidade e angústia. Ser moderno é fazer parte de um universo no qual, como disse Marx, "tudo o que é sólido desmancha no $\operatorname{ar}^{\prime \prime} .25$

Assim, é inerente à modernidade essa sensação avassaladora de fragmentação, de efemeridade e de mudança caótica, que vivemos tão intensamente na vida cotidiana. Essa transitoriedade, inclusive, dificulta a percepção do sentido de continuidade histórica, que somente pode ser descoberto com a inserção nesse turbilhão da mudança permanente.

Outro aspecto problemático é um certo milenarismo tecnológico entre os teóricos pós-modernos. Acredita-se "ingenuamente" que as mudanças e as inovações tecnológicas têm a capacidade de produzir transformações na economia e na sociedade, com o advento da chamada "sociedade pós-industrial", onde a automação da produção eliminaria a exploração e a alienação do trabalho, suprimindo-se as contradições e os conflitos fundamentais da sociedade industrial. ${ }^{26}$ Para isso, ignora-se completamente que tais mudanças não acarretam nenhuma ruptura com o modo de produção típico da sociedade moderna e que continuamos a viver em uma economia capitalista que está baseada na apropriação privada, como acumulação de capital, do excedente econômico socialmente produzido sob a forma de mercadorias. A introdução de novas tecnologias e de novas formas de organização do processo de trabalho visa à racionalização crescente 
da produção industrial, reduzindo a quantidade da força de trabalho empregada, segundo a lógica do aumento contínuo de produtividade do sistema industrial.

A informatização, pois, permite uma maior eficiência do sistema industrial. O objetivo da crescente automação é aumentar a produção e a apropriação de mais-valia relativa, substituindo-se o capital variável pelo capital constante com a elevação da composição orgânica do capital. Logo, não há nenhuma ruptura com a moderna sociedade industrial e tampouco desaparecem as contradições e os conflitos fundamentais inerentes à ordem social burguesa. Com isso, confundese o declínio do setor industrial com o declínio de todo sistema industrial, e tomam-se as novas formas de relações de trabalho, que acompanham a introdução e a difusão das novas tecnologias, como a supressão das contradições entre capital e trabalho, que assumem novas e diferenciadas modalidades de manifestação.

Por outro lado, o predomínio e a universalização da comunicação de massa são acompanhados pela produção de signos e de imagens que se autonomizaram de qualquer referente concreto, substituindo o mundo real pelo mundo artificial do simulacro. Aqui os signos são, ao mesmo tempo, auto-referentes e mais reais do que a própria realidade, que se tornou uma hiper-realidade. Dessa forma, a comunicação de massa desloca a experiência do real para a vivência no e do signo. A realidade social se desmaterializou tornando-se o domínio do signo autoreferente e o cotidiano se transformou na vivência imediata do simulacro e da hiper-realidade com a centralidade da informação na sociedade de massas.

Isso ocorre exatamente porque, com a cultura de massa que se produz com a hipertrofia e difusão extraordinária dos meios de comunicação de massa, temos a ampliação do fenômeno da reificação que penetra em todas as dimensões e interstícios da vida social, abrangendo tanto as suas instituições constitutivas quanto as suas esferas imaginárias e simbólicas. A cultura de massa transformou a imagem em significante material de primeira grandeza em nossa sociedade.

Estaríamos, assim, assistindo à emergência da "pós-modernidade" que imprimiria a marca de fragmentação, de simulacro, de efemeridade, de indeterminação, de descontinuidade, de alteridade e de ecletismo 
paradoxal a tudo e a todos. Essas mudanças se encontrariam condensadas e seriam vividas subjetivamente nas relações sociais da vida cotidiana. O cotidiano seria o espaço privilegiado de manifestação da pós-modernidade. E o resultado disso poderia ser percebido, por exemplo, nos processos em curso de desreferencialização do real, de dessubstancialização do sujeito, de desmaterialização da economia e de despolitização da sociedade.

Essa conclusão apenas é possível quando se elide as noções da alienação, do fetichismo da mercadoria e da reificação, num enquadramento sócio-histórico onde se descarta a configuração de uma ordem capitalista mundializada que a tudo e a todos subsume.

A universalização da lógica da produção de mercadorias implicou a ação paroxística da reificação sobre a cultura que se desdobrou em dois movimentos consecutivos. Num primeiro momento, a reificação destruiu os vínculos existentes entre o signo e o seu referente, resultando na "liberação" do signo que aparece como auto-referenciado. E, num segundo momento, a reificação apanha o próprio signo, constituído por significante e significado, desfazendo as suas ligações internas e liberando, por sua vez, o significante do seu significado. A partir de então, instala-se o jogo dos significantes auto-referentes, criando-se a miragem de uma linguagem de puros significantes do discurso esquizofrênico. A linguagem sofre um distúrbio e, através da quebra da cadeia de significantes e da autonomização dos significantes, passa a ser uma sucessão de significantes vazios num presente perpétuo. Com o esfacelamento do signo e a autonomização do significante, caise numa realidade social completamente fragmentada e anárquica, onde os significantes puros se configuram como "cacos" de linguagem que recaem de volta no mundo, num eterno retorno à presentificação, em decorrência do desaparecimento das noções de passado, presente e futuro que articulam a teia da história. ${ }^{27}$

A natureza dos fenômenos socioculturais contemporâneos apenas pode ser desvelada quando referida às transformações sistêmicas experimentadas pela ordem do capital a partir dos anos 80, consubstanciadas na reestruturação produtiva que afetou dramaticamente o mundo da produção, ensejando inovações na organização do processo produtivo, novas formas de gestão do trabalho, 
que buscaram legitimação ideológica e cultural no ideário neoliberal hegemônico em escala mundial. A afirmação de uma ordem capitalista verdadeiramente mundializada, onde o capital se manifesta como totalidade realizada socialmente, implicou ao mesmo tempo transformações objetivas e subjetivas. Com o esgotamento da onda longa expansiva que caracterizou o capitalismo depois da Segunda Guerra Mundial, a lógica da valorização do capital tornou imperativa a substituição do antigo regime taylorista fordista por um padrão flexível de acumulação capitalista, objetivado na reestruturação produtiva do sistema capitalista. Isso se fez acompanhar de mudanças ideológicas e culturais, altamente funcionais àquelas transformações, condensadas sob a forma, por exemplo, do ideário neoliberal e da cultura e pensamento pós-modernos, garantindo as condições superestruturais necessárias à nova ordem mundializada do capital.

Por isso, entendemos que as noções do fetichismo da mercadoria e da reificação constituem um sugestivo ponto de partida para a realização de uma crítica teórica da "cultura pós-moderna" e da emergência da "pós-modernidade" nas sociedades contemporâneas. É que o desenvolvimento do capitalismo leva ao paroxismo o fetichismo da mercadoria e produz a reificação tanto das relações sociais quanto da cultura. Assim, temos uma inversão fundamental nas relações e conexões entre o signo e o referente e entre o significante e o significado, com a autonomização, inicialmente, dos signos e, posteriormente, dos significantes. Em consequiência, a realidade foi subsumida à imagem, que passou à condição de elemento fundante de todo o real. A vida societária aparece, portanto, como mundo hipostasiado de pura especularidade e espectralidade. Enfim, como nos sugere Harvey, a cultura pós-moderna constitui o mundo como o "espelho dos espelhos". ${ }^{28}$ Decifremos o enigma da Esfinge...!!!

\section{Notas}

* Professor do Departamento de Ciências Sociais da UFRN (Universidade Federal do Rio Grande do Norte), autor do livro Crise do marxismo e irracionalismo pós-moderno (São Paulo: Cortez, 1992). Doutor em Ciências da Comunicação- USP.

${ }^{1}$ Cf. Jair Ferreira dos Santos, "O que é pós-moderno" (10 a edição. São Paulo: Brasiliense, 1991).

${ }^{2}$ Aqui, ficam evidentes as afinidades do pensamento pósmoderno com as tendências 
irracionalistas, como um dos elementos constitutivos da cultura burguesa contemporânea, através de uma drástica redução da capacidade cognoscitiva da razão e, em alguns momentos, da apologia mesmo da desrazão como projeto teórico-metodológico, que é apresentado, muitas vezes, como a última novidade intelectual. É nesta perspectiva que já nos referimos, em outra ocasião, a essas formas de pensamento como irracionalismo pós-moderno. Cf. João E. Evangelista Crise do marxismo e irracionalismo pós-moderno, cit.

3 Cf. Jean-François Lyotard, "O pós-moderno" ( 4 a edição. Rio de Janeiro: José Olympio, 1993) e David Harvey, A condição pós-moderna: uma pesquisa sobre as origens da mudança cultural (São Paulo: Loyola, 1992).

${ }^{4}$ Cf. Steven Connor, "Cultura pós-moderna: introdução às teorias do contemporâneo" (São Paulo: Loyola, 1992).

${ }^{5}$ Fredric Jameson, "Falso movimento", em Folha de S. Paulo, Caderno Mais!, p. 5, São Paulo, 19-10-1995, entrevista publicada como parte da discussão introduzida pelo presidente Fernando Henrique Cardoso sobre o "fim da cultura de massa". Nessa mesma entrevista, Jameson, sugestivamente, emprega a expressão sociedade da imagem e da informação para referir-se às sociedades capitalistas contemporâneas.

${ }^{6}$ Fredric Jameson, "Pós-modernismo: a lógica cultural do capitalismo tardio" (São Paulo: Ática, 1996).

${ }^{7}$ Ibid.

${ }^{8}$ Cf. Karl Marx, "Manuscritos econômico-filosóficos de 1844", em Florestan Fernandes (org.), Marx \& Engels (História) (São Paulo: Ática, 1989).

${ }^{9}$ Cf. Paulo Silveira, "Da alienação ao fetichismo: formas de subjetivação e de objetivação", em Paulo Silveira \& Bernard Doray (orgs.), Elementos para uma teoria marxista da subjetividade (São Paulo: Vértice, 1989).

${ }^{10}$ Para uma análise da reificação como fenômeno modelar da sociabilidade burguesa e dos seus efeitos nas formas de consciência vigentes na sociedade capitalista, continua a ser indispensável a leitura de G. Lukács, "História e consciência de classe: estudos de dialéctica marxista" (Porto: Escorpião, 1974).

${ }^{11}$ Cf. José Paulo Netto, Capitalismo e reificação (São Paulo: Ciências

Humanas, 1981)

${ }^{12}$ Cf. Karl Marx, "O Capital: crítica da economia política, vol. 1, livro 1" (2 ${ }^{\mathbf{a}}$ edição. São Paulo: Nova Fronteira, 1985).

${ }^{13}$ Cf. Karl Marx, "O Capital: crítica da economia política, vol. 1, livro 1" (2 ${ }^{\mathbf{a}}$ edição. São Paulo: Nova Fronteira, 1985).

${ }^{14}$ Cf. Paulo Silveira, "Da alienação ao fetichismo: formas de subjetivação e de objetivação", cit.

15 Cf. C. Lasch, "O mínimo eu: sobrevivência psíquica em tempos difíceis" (4 edição.

São Paulo: Brasiliense, 1987).

16 Ibid.

${ }^{17}$ C. Lasch, "A cultura do narcisismo" (Rio de Janeiro: Imago, 1983).

${ }^{18}$ Cf. Jurandir F. Costa, "O presente de nossas ilusões", em Folha de S. Paulo, São Paulo, 11-9-1994, p. 12.

${ }^{19}$ Cf. Contardo Calligaris, "O antinarciso", Caderno Mais!, em Folha de S. Paulo, São Paulo, 25-9-1994, p. 14.

${ }^{20}$ A expressão "sociedade do espetáculo" foi cunhada pelo francês Guy Debord em seu livro "A sociedade do espetáculo" (Lisboa: Afrodite, 1967) e é utilizada, entre outros, por Lasch e Jameson, para tratar dos fenômenos relativos à cultura produzida pelos 
meios de comunicação de massa nas sociedades contemporâneas.

${ }^{21}$ Contardo Calligaris, "A sedução do apocalipse”, Caderno Mais!, em Folha de S. Paulo, São Paulo, 26-3-1995, p. 15.

${ }^{22} \mathrm{Cf}$. Fredric Jameson, "Reificação e utopia na cultura de massa", em Crítica Marxista, vol. 1, no 1 (São Paulo: Brasiliense, 1994), p. 17.

${ }^{23}$ Cf. Fredric Jameson, "Marxismo e forma: teorias dialéticas da literatura no século XX" (São Paulo: Hucitec, 1985)

24 Ver Sérgio Paulo Rouanet, “A verdade e a ilusão do pós-moderno”, em “As razões do iluminismo" (São Paulo: Companhia das Letras, 1987).

${ }^{25}$ Marshall Berman, "Tudo que é sólido desmancha no ar: a aventura da modernidade"

( 9 reimpressão. São Paulo: Companhia das Letras, 1992), p. 15.

${ }^{26}$ Ver Sérgio Paulo Rouanet, "A verdade e a ilusão do pós-moderno", cit.

${ }^{27}$ Cf. Fredric Jameson, "Periodizando os anos 60", em Heloísa B. de Holanda (org.), Pósmodernismo e política ( $2^{\mathbf{a}}$ edição. Rio de Janeiro: Rocco, 1992).

${ }^{28}$ David Harvey, “A condição pós-moderna: uma pesquisa sobre as origens

da mudança cultural”, cit.

\section{Referências}

\section{Abstract:}

\section{ELEMENTS FOR A CRITICISM OF POST-MODERN CULTURE}

The text aims to develop a theoretical criticism about post-modern culture and about the appearance of post-modernity in contemporary societies. To do so, it adopt the notions of fetishism of the commodity and reification as fundamental elements to the development of this criticism, unraveling the constitutive processes of the capitalist social being, centered by the universalisation of the form of the commodity to all spheres of the social organization. It intends, also, to analyze some of the socio-cultural mechanisms that work in the model of human subjectivity and in the wide reproduction of contemporary capitalist society.

Keywords: post-modern culture; capital accumulation; fetishism; reification.

Recebido em maio/2008

Aceito em junho/2008 